\title{
PENGARUH MODEL PEMBELAJARAN DISCOVERY LEARNING TERHADAP HASIL BELAJAR FISIKA SISWA
}

Sri Wahyuni ${ }^{1}$, Adrianus Nasar ${ }^{2}$, Melkyanus Umbu Kaleka ${ }^{3}$

${ }^{1,2,3}$ Pendidikan Fisika Universitas Flores, Nusa Tengggara Timur, Indonesia

Coreresponding author email: ayuwahyunisr3@gmail.com

Info Artikel

Diterima:

7 September 2020

Disetujui:

3 Desember 2020

Dipublikasikan:

15 Desember 2020

\begin{abstract}
Abstrak:
Penelitian ini bertujuan untuk mengetahui pengaruh model pembelajaran discovery learning terhadap hasil belajar fisika siswa. Subjek penelitian adalah 30 siswa kelas X Madrasah Aliyah Muhammadiyah Riung Tahun Pelajaran 2019/2020. Jenis penelitian ini yaitu kuantitatif. Desain penelitian Ex-post facto yang bersifat kausalitas. Data yang diperoleh adalah data hasil belajar siswa pada pelajaran fisika. Analisis data yang dilakukan adalah uji normalitas dan uji t. Hasil uji hipotesis, diperoleh data t (terhitung) 9,403 nilai derajat kebebasan adalah 29.Nilai sig. (2-tailed) sebesar 0,000. Nilai signifikan (sig. 2-tailed) 0,000 $<0,05$ maka $\mathrm{H}_{0}$ ditolak dan $\mathrm{H}_{1}$ diterima (hipotesis yang diajukan diterima). Hasil perhitungan tersebut dapat disimpulkan bahwa terdapat pengaruh yang signifikan pada model discovery learning terhadap hasil belajar fisika siswa kelas X Madrasah Aliyah Muhammadiyah Riung.
\end{abstract}

Kata kunci: Model pembelajaran discovery learning, hasil belajar.

\begin{abstract}
:
This study aims to determine the effect of discovery learning learning model on student physics learning outcomes. The research subjects were 30 students of class X Madrasah Aliyah Muhammadiyah Riung in the 2019/2020 academic year. This type of research is quantitative. Expost facto research design that is causal. The data obtained are data on student learning outcomes in physics lessons. Data analysis carried out is normality test and t test. The results of hypothesis testing, obtained data $t$ (countable) 9,403 the value of degrees of freedom is 29. The value of sig. (2-tailed) of 0.000. Significant value (sig. 2-tailed) 0.000 $<0.05$ then $\mathrm{HO}$ is rejected and $\mathrm{HI}$ is accepted (the proposed hypothesis is accepted). The results of these calculations can be concluded that there is a significant influence on the discovery learning model on the physics learning outcomes of class X Madrasah Aliyah Muhammadiyah Riung.

Keywords: Discovery learning model, learning outcomes.
\end{abstract}

Copyright @ 2020 Edufisika: Jurnal Pendidikan Fisika

\section{Pendahuluan}

Pendidikan merupakan proses perubahan sikap dan perilaku secara sadar ataupun tidak sadar untuk mengembangkan kemampuan secara mandiri dengan akhlak mulia. Seluruh kalangan masyarakat dikenai dengan pendidikan dan melaksanakan pendidikan. Pendidikan didapatkan dari orang tua, lingkungan keluarga dan lingkungan masyarakat yang manakala mendidik anak dibutuhkan kesabaran dan ketulusan. Begitu pula di sekolah dan perguruan tinggi, siswa dan mahasiswa dididik oleh guru atau dosen. Pendidikan telah melekat pada diri manusia dari masa lampau hinggah saat ini. 
Sebagian besar keadaan pendidikan di Indonesia sangat memprihatinkan Indonesia berada pada salah satu tingkat paling rendah terlebih pada pelajaran sains. Dilihat dari hasil survei yang dilakukan oleh Programme For Internasional Student Asseessment (PISA) pada tahun 2018 yang diikuti oleh 79 negara. Indonesia adalah negara menempati urutan yang ke-74. Berdasarkan hasil survei mengungkapkan adanya selingan literasi meliputi tiga aspek yang dinilai, yakni kemampuan membaca, matematika, dan sains. Skor rata-rata sains di Indonesia terdaftar dalam PISA 2015 adalah 403 poin. Namun pada PISA 2018, skor rata-rata sains terdaftar adalah 396 poin (Pratiwi, 2019).

Guru tidak sekedar mengajar siswa, teteapi membelajarkan siswanya, yaitu mengkondisikan siswa agar belajar aktif dan kreatif sehingga potensi dirinya dapat berkembang dengan maksimal (Ilyas, 2017). Tugas guru yang paling penting dan menentukan adalah membimbing siswa tentang bagaimana belajar yang sesungguhnya dan belajar memecahkan masalah sehingga hal-hal tersebut dapat digunakan dimasa depan siswa. Salah satu model pembelajaran yang dapat dilakukan adalah melalui model pembelajaran yang melibatkan siswa. Siswa aktif dalam proses pembelajaran baik dari segi mental, fisik, sosial, serta sesuai dengan kondisi dalam kelas, sehingga tujuan pembelajaran dapat tercapai sesuai dengan yang diharapkan. Terdapat model pembelajaran yang melibatkan keaktifan siswa yaitu model pembelajaran discovery learning.

Gholamian (Salwan \& Rahmatan, 2018), menjelaskan bahwa model discovery learning dapat meningkatkan kreaktivitas dalam belajar, sehingga siswa tidak tergantung pada guru dan buku sebagai satu-satunya sumber belajar serta dapat menikmati proses belajar mengajar. Model discovery learning dapat membantu siswa belajar secara mandiri serta memfasilitasinya dalam menemukan berbagai ide maupun pendapat yang dimiliki sehingga suasana belajar menjadi lebih aktif. Model discovery learning mengarah pada siswa untuk mengamati, menanya, mengolah, menyajikan serta menciptakan. Sehingga dalam proses pembelajaran akan melibatkan siswa untuk menemukan sendiri berbagai konsep.

Hasil belajar ialah puncak dari suatu proses yang telah dilakukan selama belajar. Hasil belajar harus memeperlihatkan suatu perubahan tingkah laku dari peserta didik. Menurut Benyamin Bloom (Anitah et al., 2014), yang memperlihatkan hasil belajar, meliputi aspek kognitif, afektif, dan psikomotorik. Nawawi (Susanto, 2013), hasil belajar adalah sebuah tingkat keberhasilan peserta didik dalam mempelajari pelajaran di sekolah yang akan dinyatakan nilai diperoleh melalui tes materi pelajaran tersebut.

Dalam pra penelitian yang dilakukan oleh peneliti bahwa diperolehnya nilai-nilai yang rendah pada hasil ulangan harian pada pelajaran fisika. Nilai-nilai rendah yang dicapai siswa inilah yang dapat dijadikan indikator yang kuat tentang adanya pengaruh model pembelajaran terhadap hasil belajar siswa. Dan model pembelajaran yang diterapkan pada mata pelajaran fisika yaitu model pembelajaran discovery learning. Sangat penting dalam praktik pendidikan, yaitu meningkatkan pencapaian hasil belajar para siswa, mengembangkan hubungan antar kelompok, penerimaan terhadap teman sekelas yang lemah akedemik sesuatu untuk dapat merangsang kemampuan berpikir siswa serta membantu siswa memeliki ketertarikan dalam belajar fisika. Hal ini dapat dilakukan dengan menunjang kebutuhan belajar siswa. Tujuan penelitian ini untuk mengetahui pengaruh model pembelajaran discovery learning terhadap hasil belajar fisika siswa kelas X Madrasah Aliyah Muhammadiyah Riung.

\section{Metode Penelitian}

Jenis Penelitian

Jenis penelitian ini yaitu kuantitatif dengan desain penelitian Ex-post facto yang bersifat kausalitas. Penelitian Ex-post facto menunjukan perubahan variabel bebes yang terjadi (Sappaile, 2010). Penelitian ini dilakukan untuk mendeskripsikan segala sesuatu yang berkaitan dengan pengaruh model pembelajaran discovery learning terhadap hasil belajar fisika siswa kelas X Madrasah Aliyah Muhammadiyah Riung.

Tempat dan Waktu Penelitian

Penelitian ini dilaksanakan di Madrasah Aliyah Muhammadiyah Riung, Kelurahan Benteng Tengah, Kecamatan Riung, Kabupaten Ngada. Penelitian ini akan dilaksanakan pada tanggal 18-25 Juni 2020 . 
Target/Subjek Penelitian

Populasi dalam penelitian ini adalah seluruh siswa kelas X Madrasah Aliyah Muhammadiyah Riung. Sampel yang digunakan seluruh siswa kelas X IPA yang berjumlah 30 orang. Pada penelitian ini dalam menentukan pengambilan sampel yang digunakan adalah Purposive Sampling, yaitu teknik pengambilan sampel digunakan peneliti jika peneliti memepunyai pertimbangan tertentu di dalam pengambilan sampel atau penentuan sampel untuk tujuan tertentu (Sugiyono, 2017).

Prosedur

Model discovery learning sebagai variabel bebas sedangkan hasil belajar siswa sebagai variabel terikat. Hasil belajar yang diukur ranah kognitif.

Teknik dan Instrumen Pengumpulan Data

Pada penelitian ini teknik pengumpulan data adalah lembar wawancara, sedangkan instrumen pengumpulan data yang digunakan adalah dokumentasi.

Teknik Analisis Data

Dalam penelitian ini analisis deskriptif digunakan untuk mendeskripsikan data berupa rata yaitu untuk melihat nilai minimum, maksimun, mean dan standar deviasi, dari data hasil belajar siswa. Dan Analisis Inverensial yang digunakan yaitu uji normalitas untuk mengetahui apakah data hasil penelitian berasal dari populasi yang berdistribusi normal atau tidak. Pengujian normalitas dilakukan dengan menggunakan bantuan Software SPSS Versi 22 For Windows yaitu menggunakan kolmogorov smirnov. Dasar pengambilan keputusan adalah jika signifikan (sig) $>0,05$ maka data berdistribusi normal. Dalam penelitian ini menggunakan uji t satu sampel. Dasar pengambilan keputusan adalah jika signifikan (sig. 2-tiles) $<0,05$ maka $\mathrm{H}_{0}$ ditolak dan $\mathrm{H}_{1}$ diterima.

\section{Hasil Penelitian dan Pembahasan}

Data hasil belajar fisika dapat dideskriptif dengan bantuan Software SPSS Versi 22 For Windows. Hasil deskriptif variabel hasil belajar disajikan dalam Tabel 1 dibawah ini yang merangkum gambaran data hasil belajar yang telah diklasifikasikan berdasarkan kategori.

Tabel 1. Statistik Deskriptif Hasil Belajar Fisika

\begin{tabular}{cccccc}
\hline \multicolumn{6}{c}{ Descriptive Statistics } \\
\hline & $\mathrm{N}$ & Minimum & Maximum & Mean & Std. Deviation \\
\hline Hasil belajar & 30 & 70 & 95 & 81.67 & 8.543 \\
\hline $\begin{array}{c}\text { Valid N } \\
\text { (listwise) }\end{array}$ & 30 & & & & \\
\hline
\end{tabular}

Berdasarkan Tabel 1 diatas, bahwa skor maksimal hasil belajar Fisika adalah 95 sedangkan skor minimal adalah 70 dengan rata-rata 81.67 dan standar deviasi 8.543. Hasil belajar fisika siswa kelas X MA Muhammadiyah Riung, pada mata pelajaran fisika mencapai kategori baik karena melebihi standar KKM = 67 .

Berdasarkan Tabel 1 diatas, maka kategori hasil belajar yang diperoleh dapat dilihat pada Tabel 2 berikut:

Tabel 2. Kategori Hasil Belajar Siswa

\begin{tabular}{cccc}
\hline $\begin{array}{c}\text { Rentangan } \\
\text { Nilai }\end{array}$ & Kriteria & Jumlah Siswa & Persentasi(\%) \\
\hline$<67$ & Kurang Baik & 0 & 0 \\
\hline $68-78$ & Cukup Baik & 18 & 60,00 \\
\hline $79-89$ & Baik & 10 & 33,33 \\
\hline $90-100$ & Sangat Baik & 2 & 6,67 \\
\hline & Jumlah siswa & 30 & \\
\hline
\end{tabular}


Dari tabel kategori nilai hasil belajar siswa di atas bahwa, dari jumlah seluruh sampel sebanyak 30 orang.Tidak ada siswa yang mendapatkan nilai dibawah KKM. Siswa yang memperoleh nilai cukup baik dengan persentase $60,00 \%$, baik dengan persentase $33,33 \%$ sedangkan siswa yang medapatkan nilai sangat baik dengan persentase $6.67 \%$.

Berdasakan Tabel 2 kategori hasil belajar siswa dapat digambarkan dalam Diagram 1 berikut ini.

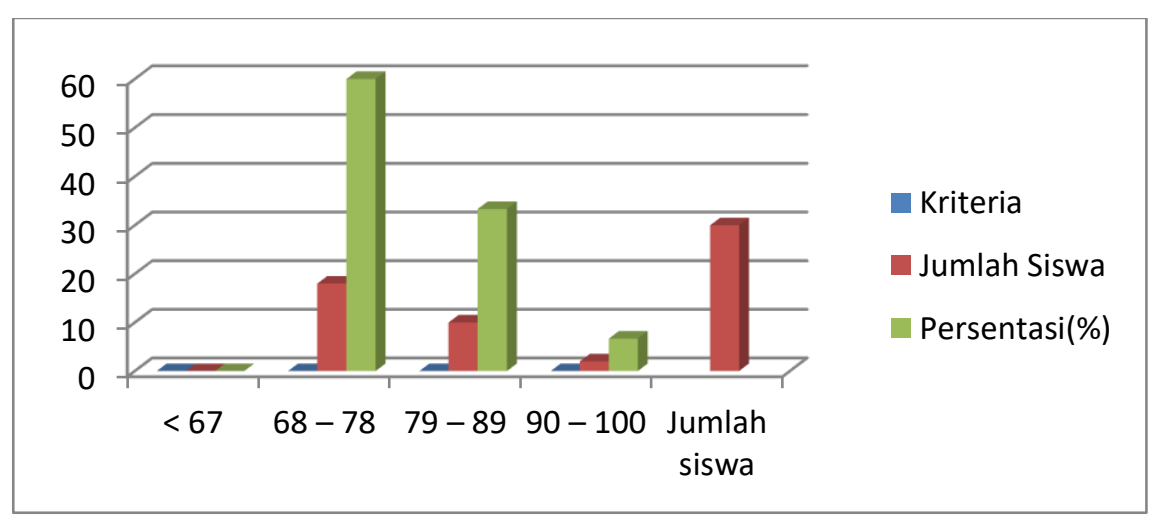

Gambar 1. Hasil Belajar Siswa

Uji normalitas data dilakukan dengan menggunakan Software SPSS Versi 22 For Windows yaitu menggunakan kolmogorov smírnov. Dasar pengambilan keputusan adalah jika signifíkan (sig) > 0,05 maka data berdistribusi normal. Hasil uji normalitas hasil belajar dapat dilihat pada Tabel 3 berikut.

Tabel 3. Hasil Normalitas Hasil Belajar

\begin{tabular}{cccc}
\hline & \multicolumn{3}{c}{ Kolmogorov-Smirnov $^{\mathrm{a}}$} \\
\cline { 2 - 4 } & Statistic & Df & Sig. \\
\hline Hasil Belajar & 0.118 & 30 & 0.200 \\
\hline
\end{tabular}

Berdasarkan hasil perhitungan pada Tabel 3 diatas dapat dilihat bahwa data normalitas uji kolmogorov smírnov diketahui bahwa hasil belajar signifikansi sebesar 0,0200. Dasar pengambilan keputusan:

1. Jika nilai signifikansi $>0,05$ maka data penelitian berdistribusi normal

2. Jika nilai signifikansi $<0,05$ maka data penelitian berdistribusi tidak normal.

Dari hasil analisis data dengan uji normalitas kolmogorov smírnov berdasarkan pengambilan keputusan uji normalitas menerangkan bahwa hasil belajar fisika siswa berdistribusi normal karena nilai sig. $0,200>0,05$.

Uji Hipotesis dalam penelitian ini menggunakan uji t satu sampel, pengujiannya dilakukan dengan bantuan Software SPSS Versi 22 For Windows.

Tabel 4. Hasil Uji Hipotesis

\begin{tabular}{lcccccc}
\hline \multicolumn{8}{c}{ One-Sample Test } \\
\hline & \multicolumn{7}{c}{ Test Value $=67$} \\
\cline { 2 - 7 } & $\mathrm{t}$ & df & Sig. (2-tailed) & $\begin{array}{c}\text { Mean } \\
\text { Difference }\end{array}$ & $\begin{array}{c}\text { 95\% Confidence Interval } \\
\text { of the Difference }\end{array}$ \\
\hline Hasil Belajar & 9.403 & 29 & .000 & 14.667 & 11.48 & 17.86 \\
& & & & & Lower & Upper \\
\hline
\end{tabular}

Berdasarkan Tabel 4 One sampel diatas diketahui nilai t (terhitung) 9,403 nilai derajat kebebasan adalah 29. Nilai sig. (2-tailed) sebesar 0,000. Nilai signifikan (sig. 2-tailed) $0,000<0,05$ 
maka $\mathrm{H}_{0}$ ditolak dan $\mathrm{H}_{1}$ diterima (hipotesis yang diajukan diterima). Nilai yang diambil pada uji hipotesis ini adalah nilai yang diperoleh dari penilaianulangan harian pada materi hukum newton tentang gerak. Dari nilai yang diperoleh, dapat diketahui bahwa ada pengaruh penggunaan model pembelajaran discovery learning terhadap hasil belajar fisika siswa kelas X Madrasah Aliyah Muhammadiyah Riung.

Pengumpulan data dalam penelitian ini dilakukan dengan dokumentasi hasil belajar siswa, merupakan nilai ulangan harian siswa pada materi hukum newton tentang gerak yang mencapai KKM. Nilai ulangan harian tersebut dianalisis mengunakan Software SPSS Versi 22 For Windows. Sedangkan hasil wawancara kepada guru mata pelajaran fisika sebagai penguat bahwa model discovery learning berpengaruh terhadap hasil belajar siswa. Hasil wawancara dengan guru mata pelajaran fisika yang mengatakan bahwa model pembelajaran ini berpengaruh terhadap hasil belajar siswa hal ini dikarenakan sebagaian besar nilai hasil belajar siswa telah mencapai KKM.

Uji hipotesis dilakukan dengan uji-t One sampel diatas diketahui nilai t (terhitung) 9,403 nilai derajat kebebasan adalah 29.Nilai sig. (2-tailed) sebesar 0,000. Nilai signifikan (sig. 2-tailed) 0,000 < 0,05 maka $\mathrm{H}_{0}$ ditolak dan $\mathrm{H}_{1}$ diterima (hipotesis yang diajukan diterima). Hasil penelitian ini menunjukan bahwa ada pengaruh penggunaan model pembelajaran discovery learning terhadap hasil belajar fisika siswa kelas X Madrasah Aliyah Muhammadiyah Riung. Bahwa dengan penggunaan model discovery learning merupakan salah satu bagian dari pembelajarandiscovery yang banyak melibatkan siswa dalam kegiatan belajar mengajar, namun dalam proses penemuan siswa mendapat bantuan atau bimbingan dari guru, agar mereka lebih terarah sehingga baik proses pelaksanaan pembelajaran maupun tujuan yang dicapai terlaksana dengan baik.

Uji normalitas dan uji hipotesis pada penelitian ini model discovery learning adalah model pembelajaran yang sesuai dengan karakteristik siswa, karena hal ini dapat meningkatkan hasil belajar yang lebih tinggi. Salah satunya dengan menerapkan model pembelajaran discovery learning yang memiliki pengaruh lebih besar terhadap keaktifan dan hasil belajar siswa dalam ranah kognitif, khususnya dalam mata pelajaran fisika.

Dan ditinjau dari penelitian sebelumnya (Kadri \& Rahmawati, 2015), dengan judul pengaruh model pembelajaran discovery learning terhadap hasil belajar siswa pada materi suhu dan kalor, bahwa penelitian menunjukan adanya keberhasilan penggunaan mode ldiscovery learning. Model discovery learning merupakan konsep pembelajaran yang mengutamakan keaktifan siswa selama kegiatan belajar mengajar.Dalam sistem belajar mengajar ini guru menyajikan bahan pelajaran yang tidak berbentuk final, tetapi anak didik diberi peluang untuk mencari dan menemukan sendiri dengan menggunakan teknik pendekatan pemecahan masalah

\section{Simpulan}

Hasil uji hipotesis, diperoleh data t (terhitung) 9,403 nilai derajat kebebasan adalah 29.Nilai sig. (2-tailed) sebesar 0,000. Nilai signifikan (sig. 2-tailed) 0,000 <0,05 maka $\mathrm{H}_{0}$ ditolak dan $\mathrm{H}_{1}$ diterima (hipotesis yang diajukan diterima). Berdasarkan hasil penelitian ini dapat disimpulkan bahwa terdapat pengaruh yang signifikan pada model discovery learning terhadap hasil belajar fisika siswa kelas $\mathrm{X}$ Madrasah Aliyah Muhammadiyah Riung.

\section{Referensi}

Anitah, S., Julaeha, S., \& Wardani. (2014). Strategi Pembelajaran di SD. Tangerang selatan :Universitas Terbuka.

Ilyas. (2017). Hubungan Kecerdasan Emosional Dan Motivasi Belajar Fisika Dengan Hasil Belajar Fisika Peserta Didik Kelas X SMA Negeri 1 Tinggimoncong. Ilyas. Jurnal Ilmiah Dinamika Sains, 1(3), 27-32.

Kadri, M., \& Rahmawati, M. (2015). Pengaruh Model Pembelajaran Discovery Learning Terhadap Hasil Belajar Siswa Pada Materi Pokok Suhu Dan Kalor. Jurnal Ikatan Alumni Fisika, 1(1), 2933. https://doi.org/10.24114/jiaf.v1i1.2692

Pratiwi, I. (2019). Efek Program Pisa Terhadap Kurikulum Di Indonesia. Jurnal Pendidikan Dan 
Kebudayaan, 4(1), 51-71. https://doi.org/10.24832/jpnk.v4i1.1157

Salwan, S., \& Rahmatan, H. (2018). Pengaruh Lkpd Berbasis Discovery Learningterhadap Peningkatan Hasil Belajar Siswa. Jurnal Pendidikan Sains Indonesia, 5(2), 25-31. https://doi.org/10.24815/jpsi.v5i2.9812

Sappaile, B. I. (2010). Konsep Penelitian Ex-Post Facto. 1(2), 105-113.

Sugiyono. (2017). Metode Penelitian Kuantitatif, Kualitatif dan R\&D. Bandung: Alfabeta, CV.

Susanto, A. (2013). Teori Belajar \& Pembelajaran di Sekolah Dasar. Jakarta: Prenadamedia Group. 